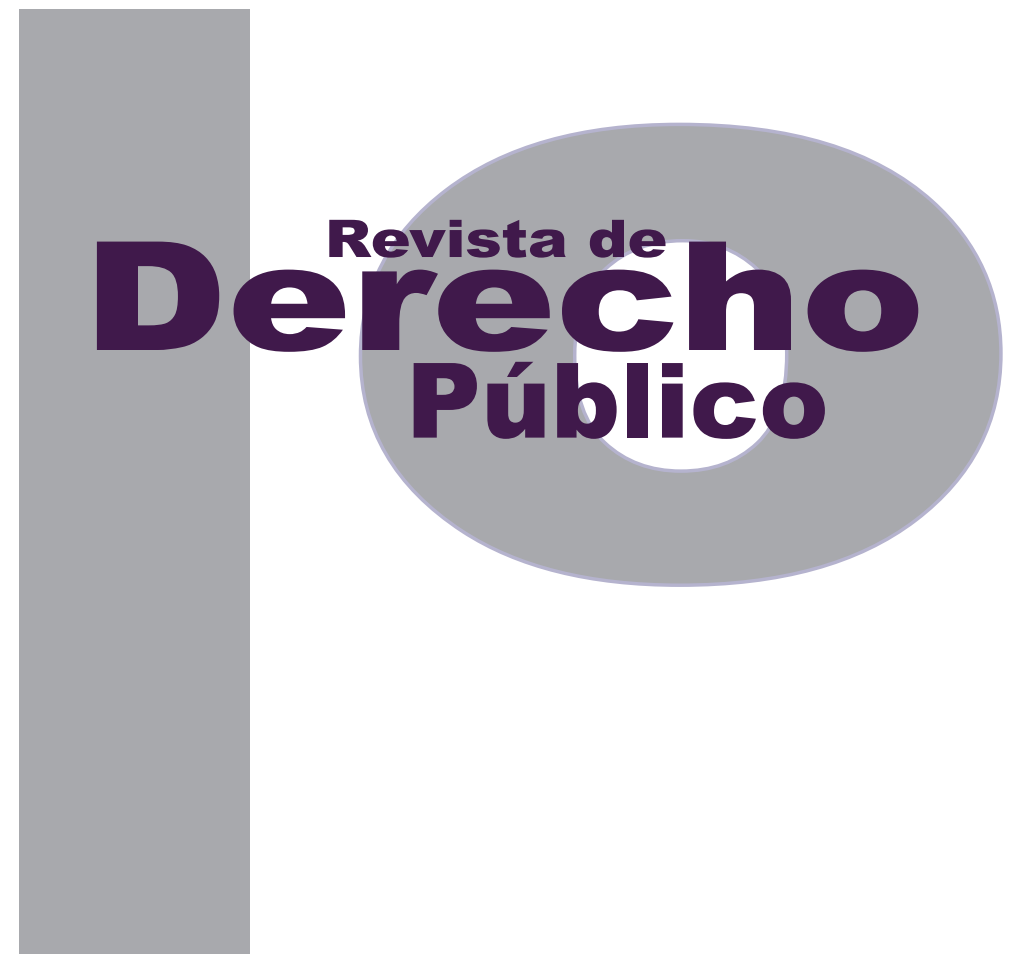

\title{
AUTÉNTICO ORDEN PÚBLICO INTERNACIONAL DESDE LA ÓPTICA DEL ARBITRAJE INTERNACIONAL
}

\author{
Francesco Zappalá
}

Artículo de reflexión

DOI: http://dx.doi.org/10.15425/redepub.34.2015.33

Universidad de los Andes

Facultad de Derecho

Revista de Derecho Público N. ${ }^{\circ} 34$

Enero - Junio de 2015. ISSN 1909-7778 


\section{Auténtico orden público internacional desde la óptica del arbitraje internacional}

\section{Resumen}

El principio de la autonomía de la voluntad privada en el ámbito contractual, para efectos del derecho procesal aplicable, es un axioma en las relaciones de comercio transnacionales. No obstante, en diversos sistemas jurídicos pueden encontrarse límites a este principio que residen en las normas de orden público. Es posible individuar los principios de orden público como aquellos que inspiran un determinado ordenamiento jurídico y que reflejan los valores esenciales de una sociedad. El concepto responde a una idea general de supremacía de la sociedad sobre el individuo. Este documento tiene como objetivo demostrar la preponderancia de la voluntad contractual en el plano transnacional sobre la denominada lex arbitri. La metodología usada es de naturaleza documental.

Palabras clave: arbitraje internacional, orden público y autonomía de la voluntad privada.

\section{Authentic International Public Policy from International Arbitration Scene}

\section{Abstract}

The principle of the autonomy of the contract will in the choice of procedure law is an axiom in international trade disputes. Nevertheless, in several legal systems there are restrictions to this principle residing in the public policy. It is possible to identify the principles of public policy such as those that inspire a particular jurisdiction and are an echo of the fundamentals values of a society. The concept responds to a general idea of the supremacy of society over individuals. This paper purports to demonstrate the prevalence of contractual intent over the so-called lex arbitri at the transnational level. The methodology used is documentary.

Keywords: international arbitration, public policy and autonomy of the contract will.

\section{Autêntica ordem pública internacional desde a ótica da arbitragem internacional}

\section{Resumo}

O princípio da autonomia da vontade privada no âmbito contratual, para efeitos do direito processual aplicável, é um axioma nas relações de comércio transnacionais. Não obstante, em diversos sistemas jurídicos podem encontrar-se limites a este princípio que residem nas normas de ordem pública. É possível individuar os princípios de ordem pública como aqueles que inspiram um determinado ordenamento jurídico e que refletem os valores essenciais de uma sociedade. 0 conceito responde a uma ideia geral de supremacia da sociedade sobre o indivíduo. Este documento tem como objetivo demostrar a preponderância da vontade contratual no plano transnacional sobre a denominada lex arbitri. A metodologia usada é de natureza documental.

Palavras-chave: arbitragem internacional, ordem pública e autonomia da vontade privada. 


\title{
Auténtico orden público internacional desde la óptica del arbitraje internacional ${ }^{*}$
}

\author{
Francesco Zappalá**
}

\section{SUMARIO}

Introducción - I. CONTEXTUALIZACIÓN DE LA PROBLEMÁTICA DEL ORDEN PÚBLICO INTERNACIONAL EN LAS RELACIONES CONTRACTUALES TRANSFRONTERIZAS - A. Origen y concepto de orden público - B. El orden público en la teoría conflictualista - C. Problemas generados por el orden público en las relaciones transfronterizas - D. Imperfectos antecedentes judiciales en materia de orden público - II. PRECISIÓN DEL CONCEPTO DE ORDEN PÚBLICO INTERNACIO$\mathrm{NAL}$ - A. Orden público procesal - B. Orden público en instrumentos de arbitraje internacional - C. Estado transgresor del orden público - D. Orden público internacional y normas imperativas - III. ANACIONALIDAD DEL ORDEN PÚBLICO INTERNACIONAL - A. Auténtico orden público internacional - B. Paradigmas de orden público internacional - IV. CONCLUSIONES - Referencias.

* Cómo citar este artículo: Zappalá, F. (Junio, 2015). Auténtico orden público internacional desde la óptica del arbitraje internacional. Revista de Derecho Público, 34. Universidad de los Andes (Colombia).

\footnotetext{
Artículo realizado en el marco del proyecto de investigación "El antagonismo de la Lex Arbitri y la autonomía contractual en el arbitraje internacional", financiado por la Pontificia Universidad Javeriana de Cali, en el ámbito del grupo de investigación Instituciones Jurídicas y Desarrollo, categorizado por Colciencias.

** Abogado de la Universidad de San Buenaventura, Cali, Colombia. Magíster en Diritto Privato Europeo de la Università degli Studi La Sapienza Roma, Italia; tesis cum lode; título: Arbitrato di Consumo. Doctorando último año en Diritto dell'Economía e dell'Impresa del Colegio Doctoral en Derecho Comercial de la Università degli Studi La Sapienza Roma; tesis sobre arbitraje comercial internacional. Especialista en Derecho Comercial de la Universidad Pontificia Bolivariana de Medellín, Colombia. Profesor del Departamento de Ciencia Jurídica y Política, y de la Maestría en Derecho Empresarial de la Pontificia Universidad Javeriana, Cali, Colombia. Profesor invitado del Máster in Diritto Privato Europeo dell'Università degli Studi La Sapienza, en el módulo: Arbitrato Commerciale Internazionale. Correo: fzappala@javerianacali.edu.co Vínculo Colciencias: http://201.234.78.173:8081/cvlac/visualizador/generarCurriculoCv.do?-cod_rh=0001223569
} 


\section{Introducción}

En las relaciones internacionales el principio de la autonomía de la voluntad o libertad de las partes para elegir el derecho que regirá los aspectos procesales en caso de controversia es un axioma indiscutible en la actualidad, sin embargo el orden público representa en algunos sistemas jurídicos una limitación al principio mencionado.

El orden público representa los valores predominantes de una sociedad, que iluminan un ordenamiento jurídico determinado. No es perfectamente diáfano el alcance jurídico de la acepción 'orden público', por lo que es imperativo demarcar su significado y determinar su ámbito de aplicación, al igual que identificar sus distintas ramificaciones, en específico las dos vertientes nacional e internacional. Al efecto, es preciso acudir a los antecedentes emblemáticos y a las tendencias doctrinarias prevalecientes, de los cuales ha surgido la expresión orden público internacional. El orden público internacional presenta, a su vez, un carácter sustantivo y otro procesal, que tiene como axiología la obligatoriedad de garantizar un due process transnacional, que consiste en el respeto a la igualdad de las partes y el derecho a tener acceso al debate contradictorio.

En mérito al grado de amplitud y control del orden público en relación con la autonomía de la voluntad privada en la esfera del arbitraje internacional florecen dos tesis: tesis maximalista y tesis minimalista. La primera postula una concepción amplia del orden público internacional, que se inclina a vigilar de fondo el arbitraje internacional y sus laudos, argumentando la predominancia de las normas de public policy nacionales; la otra, en cambio, considera que la intervención del orden público debe ser mínima.

Igualmente, es menester distinguir entre orden público local y orden público internacional. El primero es más amplio que el segundo, mientras el orden público local versa sobre las nociones básicas de moralidad y de justicia nacionales, el orden público internacional es aquel aceptado por la comunidad internacional.

\section{CONTEXTUALIZACIÓN DE LA PROBLEMÁTICA DEL ORDEN PÚBLICO INTERNACIONAL EN LAS RELACIONES CONTRACTUALES TRANSFRONTERIZAS}

El principio de la autonomía de la voluntad, o libertad de las partes para elegir el derecho que regirá los aspectos procesales en caso de controversia, es un axioma en las vinculaciones mercantiles transfronterizas. No obstante, en los distintos sistemas jurídicos pueden encontrarse límites a la mencionada autonomía en el denominado orden público.

El orden público ha sido calificado como el enfant terrible del derecho internacional privado (Kahn-Freund, 1974, pág. 29). La problemática del orden público se presta a confusión, debido, en parte, a la disparidad terminológica sobre la cuestión, visto que es un tema en que intervienen recíprocamente diversas doctrinas del com- 
mon law y del derecho civil continental europeo, a lo que deben agregarse las divergencias existentes incluso entre los distintos regímenes jurídicos. La materia, de por sí difícil, resulta más oscura debido a las imprecisiones, la diversidad y la confusión en el vocabulario utilizado (Lalive, 1986).

Entre la autonomía contractual, específicamente en mérito a la elección del derecho procesal aplicable al arbitraje internacional, y el orden público ha existido desde hace casi dos siglos una relación conflictiva, al punto que la mayor parte de la doctrina y la práctica jurisdiccional las presentan como figuras antagónicas. La complejidad se amplifica si consideramos la relatividad, vaguedad e inestabilidad del concepto de orden público, comparado con el mayúsculo dinamismo y adaptación del instituto arbitral internacional.

La causa principal de la distancia entre ambas instituciones no se encuentra en el origen del arbitraje, que existe concomitantemente con la civilización desde milenios antes de la aparición del Estado, que es el origen, refugio y finalidad del orden público. Antes de la invención del Estado moderno, el arbitraje, en una concepción equivalente a la actual, convivía perfectamente con el sistema de justicia.

La creación de la función jurisdiccional del Estado moderno inauguró el recelo y el escrúpulo, injustificados, del Estado hacia el arbitraje, que compite y resulta vencedor ante la lentitud, corrupción y desconfianza del aparato judicial, y despoja al Estado del poder presuntamen- te omnímodo y monopolizador de solución de controversias.

La liberalización del comercio o globalización, o también mundialización, genera la necesidad de una forma de solución de controversias que la odiosa y añeja función judicial no es capaz de satisfacer, y encuentra la respuesta en el antiguo pero eficaz y atractivo arbitraje. Sin embargo, el arbitraje para poder convertirse en la forma de solución de controversias transnacionales debe descargarse de todos los estorbos, entre los que se encuentra el orden público, concebido como una ficción que tiene su razón de ser en la desconfianza contractual de los individuos y en la convicción de que estos son mentecatos e ignorantes contractuales, situación que en el escenario nacional puede ser cierta, pero no en el plano internacional, en donde no existen débiles, ni inexpertos, ni tanto menos ingenuos en la materia contractual.

Ante la impotencia y aprensión del Estado por perder el poder jurisdiccional en asuntos internacionales, muchos de los iuspublicistas y desconocedores de la teoría y de la práctica arbitral internacional impulsaron la ficción de la preocupación por un inexistente "lado oscuro" (Vásquez, 2006, págs. 407-410) de este. Para justificarlo, indoctamente trasladaron las problemáticas del arbitraje interno al arbitraje internacional, impulsados por visiones provinciales del derecho que no permiten entenderlo en este nuevo contexto, planteando perplejidades sobre un principio que tiene milenios de antigüedad y que antes del nacimiento del Estado moderno permitió a la civilización sobrevivir al 
conflicto: la autonomía contractual en aspectos procesales.

Se forja de esta forma el paladín de la lucha contra la autonomía contractual en aspectos procesales del arbitraje: el orden público mal denominado internacional.

Quien escribe no es ajeno al entendimiento de que es necesario establecer límites y precauciones frente a la amenaza de fragmentación que la denominada globalización de la economía pueda generar entre el poder económico de la necesaria inversión extranjera y los principios básicos de justicia, admitiendo que el principal perjudicado de sus abusos sería el mismo arbitraje internacional. La solución es el auténtico orden público internacional que representa el legítimo freno a la posible extrema autarquía del contractualismo salvaje y es garantía de justicia en el arbitraje internacional, lo que permite que el arbitraje se nutra de sus principales características, entre las que se encuentra la autonomía contractual, particularmente en los asuntos procesales. El auténtico orden público internacional permite disponer de todas las cualidades del arbitraje internacional y limitarlo de sus eventuales abusos.

El arbitraje ha sido terreno fértil para el desarroIlo y refinamiento reciente de la compleja noción del orden público, en consideración a que el binomio arbitraje-orden público seduce a teóricos y prácticos por la cantidad de disciplinas que en él se entrecruzan, pues envuelve cuestiones de orden procesal, contractual, internacional privado y público y de derecho comparado, además de encontrarse en el centro de debates filosóficos, dado que se presentan los problemas fundamentales del derecho: la justicia, sus formas y finalidades; la juridicidad, sus fuentes y su naturaleza; la estructura del ordenamiento jurídico y la axiología del derecho (Oppetit, 2006, pág. 248).

Estos temas han sido objeto de profundas modificaciones en tiempos recientes en que el arbitraje vuelve a cobrar importancia. Los mercantes del Medioevo sometían sus controversias a sus propios pares. Es decir, a otros comerciantes o a terceros, pero la consolidación de los EstadosNaciones y el avance de las ideas de soberanía estatal desde el inicio del siglo XIX hasta el final de la Segunda Guerra Mundial, entre otros factores, contribuyeron a que se prescindiera del arbitraje. El escenario cambia por completo en las últimas décadas, en que el arbitraje comercial internacional adquiere mayor preponderancia y difusión, se utiliza masivamente en importantes controversias transfronterizas relacionadas con la compraventa internacional de mercaderías, commodities, joint ventures y contratos de construcción, diferenciándose del arbitraje doméstico, en razón de su especificidad, funciones y caracteres principales.

La mundialización exige la necesidad de un orden público internacional que, para ser legítimo, no puede tener origen en el concepto limitado de Estado, sino que debe desbordar los confines nacionales, debe romper con el reduccionismo intelectual de quienes creen que el derecho estatal representa el universo jurídico, debe ser entendido como supranacional y debe conglo- 
bar el orden público interno de cada Estado. Es decir, debe ser auténticamente internacional.

\section{A. Origen y concepto de orden público}

Es posible individualizar los principios de orden público como aquellos que inspiran un ordenamiento jurídico determinado y que son reflejo de los valores esenciales de una sociedad (Angelini, 2007, págs. 1-4). La idea general responde a una supremacía de la sociedad sobre el individuo, y el orden público traduce la voluntad comunitaria, amenazada por determinadas iniciativas individuales en forma de contrato. Es, en realidad, un mecanismo mediante el cual el Estado reprime las convenciones particulares que puedan atentar contra sus intereses esenciales (Carbonnier, 1971, pág. 266) y responde a un fuerte interés político o guarda relación con las políticas públicas de un país, tanto para la consecución de objetivos sociales y económicos como para la protección de las partes consideradas débiles y, en consecuencia, necesitadas de tutela.

La expresión orden público fue incluida en el artículo 6 del Code Civil francés de 1804 y se extendió a numerosos cuerpos legales. Algunos lingüistas explican el motivo por el que los europeos continentales denominan orden público a lo que los más pragmáticos angloamericanos llaman public policy, argumentando que el Code Napoleón utilizó la expresión orden público y no política pública (politique publique), con la que se hizo conocida en el continente europeo (Van Houtte, 2002, pág. 842), para depurar el derecho de concepciones eminentemente políticas, en consideración al difícil escenario político del momento.

La codificación alemana utiliza las expresiones leyes imperativas (Leges Obligatorisch), buenas costumbres, Moral. En el Bürgerliches Gesetzbuch alemán se excluyó el concepto de orden público que había sido propuesto inicialmente por la comisión redactora, debido a su carácter ideológico, y se mantuvieron los términos Moral, bien general, Allgemeininteresse, aunque finalmente la jurisprudencia terminó equiparando estos términos al concepto de orden público (Enneccerus, Kipps y Wolff, pág. 53).

\section{B. El orden público en la teoría conflictualista}

El orden público representa un componente cardinal en la disciplina iusprivatista internacional. En la Edad Media se identificaba con el vocablo statuta odiosa la norma foránea que debía ser excluida por incompatible con el propio sistema, cuando pudiera ocasionar un perjuicio a los poderes o derechos del gobierno o de sus súbditos (Lipstein, 1982, pág. 12). El orden público representa conceptos fundamentales sobre los que se asienta el ordenamiento jurídico del Estado, como los denominados principios de moralidad y justicia, de justicia universal y de natural justice, inspiradores del ordenamiento. Se trata de normatividad local que no puede derogarse por la voluntad de las partes (Caivano, 1998, pág. 156), conforme a la cual los intereses privados se encuentran gobernados por el derecho del Estado y es aplicada siempre dentro del territorio del Estado concernido. Esta 
noción es recogida por el Codice Civile italiano de 1865, por el Código Civil español, al igual que por el artículo 14 del Código Civil argentino (Kegel, 1986, pág. 8).

Por el contrario, existe un camino directo designado “mejor derecho", que permite obtener directamente el derecho aplicable sin recurrir a las técnicas del conflictualismo, en donde no encuentra cabida la noción de orden público.

El sistema conflictualista consiste en asumir que ciertas normas o principios del foro resultan fundamentales y deben ser aplicados siempre dentro de su jurisdicción. El orden público es el factor positivo, y no es la excepción en relación a la aplicación del derecho que hubiera resultado normalmente aplicable (Juenger, 2000, págs. 171 y ss.). Desde la visión del orden público, este no objeta la aplicación del derecho extranjero, sino que es imposible no aplicar las reglas del foro. Actualmente, la doctrina desarrolla el aspecto del orden público refiriéndose a las lois de pólice (Fouchard, Gaillard y Goldman, 1996, pág. 847) u otras expresiones como normas imperativas, de aplicación inmediata, y términos análogos.

\section{Problemas generados por el orden público en las relaciones transfronterizas}

El concepto de orden público constituye una seria amenaza a la colaboración internacional en el campo del conflicto de leyes (Gutteridge, 1949, pág. 161). El principio de orden público, como se encuentra concebido, en realidad no es moldeado por influencias jurídicas, sino marcado por ideologías sin exactitud, ni estándares fijos.

El concepto de orden público, al igual que el de arbitrabilidad, se nutren de sensibilidades locales, que los convierten en indeterminados, pues admiten interpretaciones no solo distintas, sino contradictorias e inclusive peligrosas.

En algunas ocasiones el orden público, debido a sus contornos vagos e imprecisos, ha sido utilizado como "válvula de escape" para introducir justicia "por la puerta de atrás", cuando las reglas del sistema conflictualista llevarían a un resultado injusto o inadmisible (Visher, 1993, pág. 106).

El orden público alimentado de abstracciones dogmáticas se convierte en la fuente de justificaciones para facilitar el triunfo de vanidosos nacionalismos que agravan el aislamiento de los propios nacionales inmersos en la sociedad universal, en detrimento de la inversión internacional y del progreso ineluctablemente mundializado, porque es innegable que la confusión generada por la falta de precisión y justa consideración del orden público internacional, aplana el terreno para la dificultad del reconocimiento de laudos arbitrales internacionales, con la consecuente abstención de inversión extranjera y temor de contratación internacional.

En las relaciones jurídicas transfronterizas, el orden público internacional debe ser apreciado de manera menos rigurosa que el orden público interno. 
Gran parte de los comentaristas de origen conflictualista afirman que el orden público internacional incluye los principios fundamentales relativos a justicia y moralidad que el Estado desea proteger, y la reglamentación designada para servir los intereses políticos, sociales y económicos del Estado, conocidos como leyes de policía o reglas de orden público (González de Cossío, 2008, págs. 65 y ss.). Esta afirmación es equivocada porque precisa el concepto de orden público internacional desde la visión de un Estado, asimilando inexactamente orden público interno con orden público internacional, cuando en realidad es solo orden público interno. La demostración de su desacierto se encuentra en que si, por absurdo, fuera posible que cada país estableciera el concepto de orden público internacional, existirían tantos órdenes públicos internacionales como países. Conclusión imposible.

\section{Imperfectos antecedentes judiciales en materia de orden público}

En muchas ocasiones el orden público es utilizado como justificación para rechazar el derecho foráneo, convirtiéndolo así en instrumento para una hipócrita censura de este. Existe una tendencia jurisprudencial (homing trend) de los tribunales que consiste en aplicar forzosamente el derecho propio. Señala ella que los principios o normas internas de un Estado deben ser aplicados aun cuando se trate de una situación transnacional (Cárdenas, 2007, pág. 79). Según esta posición, que considero inoportuna, se deben forzosamente aplicar los principios de la normatividad interna o la ley nacional a una situación que tenga el carácter de internacional.
En el mismo sentido, el Second Circuit of U.S. Court of Appeals (caso Parsons \& Whittermore Overseas Co. Inc. vs. Societé de L'Industrie du Papier), señaló que la ejecución de un laudo podía negarse cuando con ella se violaran los conceptos más básicos de moralidad y justicia del respectivo Estado.

El Tribunal de Justicia Europeo expresó que, de conformidad con la Convención de Bruselas sobre Jurisdicción y Reconocimiento de Ejecución de Sentencias en Materia Civil y Mercantil, cabe aplicar la negativa de violación del orden público cuando el reconocimiento o la ejecución de la sentencia en otro Estado pudiese discrepar en grado inaceptable del orden jurídico del Estado en el que se pretenda la ejecución, en cuanto viole un principio fundamental. La infracción tendría que constituir una violación manifiesta de una norma de derecho considerada esencial en el orden jurídico del Estado en el que se pretenda la ejecución, o de un derecho reconocido como fundamental de dicho ordenamiento jurídico.

Al respecto, la Corte Suprema de Justicia de Colombia, Sala Civil, en sentencia 11001-0203000-2001-0190-01 de 6 de agosto de 2004 ha expuesto que la noción de orden público debe usarse para evitar que una sentencia o ley extranjera tenga que ser acogida cuando contradiga principios fundamentales. Cuando una ley extranjera o la sentencia que la aplica se basan en principios no solo diferentes, sino contrarios a las instituciones fundamentales del Estado en que aquellas pretenden aplicarse, los jueces del Estado pueden negarse a aplicar la ley o el fallo 
extranjero que se aparta de principios del orden público interno.

La Cour d'Appel de París también se refirió al orden público internacional en el caso Renosol France vs. Société Corevall North America, 15 febrero 1992, al señalar que se trata de reglas y valores de los cuales el derecho francés no puede sufrir desconocimiento, aun en situaciones internacionales.

En algunos países, como Suiza, la jurisprudencia de su Tribunal Fédéral en la sentencia 4P.278, 8 mar. 2006, indica que el orden público internacional va más allá, pues se refiere a principios que son transnacionales. En tal sentido, dicho Tribunal ha manifestado que se viola el orden público si la decisión es contradictoria o transgrede principios jurídicos fundamentales al punto de no ser conciliable con el orden jurídico y el sistema de valores determinante (Cárdenas, 2007, pág. 80).

\section{PRECISIÓN DEL CONCEPTO DE ORDEN PÚBLICO INTERNACIONAL}

El gran desafío es aclarar la terminología del orden público, delimitar apropiadamente el principio y establecer pautas específicas de su aplicación y de sus distintas derivaciones, atendiendo las regulaciones preponderantes existentes en el mundo, fallos y laudos emblemáticos y las tendencias doctrinarias prevalecientes. Para cuestiones de derecho transfronterizo se ha acuñado la expresión orden público internacional.
Un importante estudio europeo relativo a propuestas de reforma en el ámbito contractual, conocido como Libro Verde (Autorino, Noviello y Troisi, 2013, pág. 25), señala la distinción entre orden público interno e internacional, y afirma que el orden público interno es el conjunto de normas nacionales de carácter imperativo cuyo objeto es garantizar el orden social y económico de un Estado. Es decir, se trata de normas cuya aplicación las partes no pueden excluir por la vía contractual. Por ejemplo, las destinadas a proteger una parte considerada débil, como puede ser el consumidor, el trabajador o el menor. $Y$ el orden público internacional debe entenderse como el conjunto de preceptos que la comunidad mundial considera necesarios para garantizar los estándares mínimos de justicia y evitar los abusos derivados de la libertad de contratación.

Del caso Messageries Maritimes, de donde claramente surge un ius gentium paralelo al derecho común doméstico, se desprende que las funciones y el propósito del orden público en el derecho doméstico y en el internacional no son iguales. Una norma imperativa doméstica no necesariamente prevalece en cuestiones internacionales. Efectivamente, en el caso mencionado, la Cour de Cassation francesa (1959), determinó sobre un préstamo en dólares-oro canadienses de una compañía de ese país a Messageries Maritimes, la que intentó pagar a sus tenedores de bonos con dólares de papel, conforme a la ley canadiense entrada en vigor luego de la fecha de la deuda. Dicha ley devaluó el dólar y prohibió cláusulas-oro, sin distinguir entre pagos internos e internacionales. La Corte 
de Casación la ignoró y pronunció que las partes podían acordar, aún contra normas imperativas de derecho interno gobernando el contrato, una cláusula-oro válida bajo el derecho francés, de conformidad con el sentido interno de orden público internacional. El caso creó así una nueva regla, la de validez de las cláusulas-oro en contratos internacionales, diferente a la regla francesa aplicable a pagos domésticos (Fauvarque-Cosson, 2008, págs. 113-114).

Existe una corriente de opinión que distingue entre orden público local y orden público internacional. El primero es más amplio que el segundo. Mientras que el orden público local versa sobre las nociones más básicas de moralidad y de justicia, el orden público internacional es aquel aceptado por la comunidad internacional.

En Estados Unidos tres antecedentes jurisprudenciales (leading cases) de la Supreme Court dejaron establecida la distinción entre orden público interno e internacional. En The Bremen vs. Zapata Offshore Co., de 1972 (Caso The Bremen vs. Zapata Offshore Co., U.S. Supreme Court, N. 71-322, 12 junio 1972) se estableció que el derecho doméstico no prevalece en el comercio internacional. En el caso Scherk vs. Alberto-Culver Co., de 1974 (Caso The Scherk vs Alberto-Culver Co., U.S. Supreme Court, N. 73-781, 17 junio 1974) ha sido reconocida la validez de la cláusula arbitral considerando el carácter internacional del contrato, excluyendo las restricciones impuestas por la normatividad bancaria nacional, Securites Exchange Act, es decir, la arbitrabilidad. En el caso Mitsubishi Motor Corp. vs. Soles Chrysler-Plymouth Inc., de
1985 (Caso The Mitsubishi Motor Corp. vs. Soles Chrysler-Plymouth Inc., U.S. Suprme Court, N. 83-1569, 2 julio 1985), se destaca que las normas domésticas imperativas de arbitrabilidad en materia de competencia desleal se excluyen a favor de las relaciones internacionales.

La noción de orden público internacional se encuentra recogida en los artículos 1498 y 1502 del Code de Procédure Civile francés; en el artículo 1096 literal f del Código de Processo Civil portugués de 1986 y también en la legislación de Algeria, Líbano y Paraguay. En Rumania y Túnez la legislación alude al orden público como se lo entiende en el derecho internacional privado. Algunas legislaciones hablan también de orden público y moral, como Japón, Libia, Omán, Qatar, Emiratos Árabes Unidos y Yemen (Ahdab y El Ahdab, 2011, págs. 21-24). También se considera que admite la noción de orden público internacional, si bien utilizando la terminología de orden público, la Ley Modelo de Arbitraje de la United Nations Commission for the Unification of International Trade Law (UNCITRAL), en el artículo 34, numeral 2, literal b, sección ii. Debe advertirse que la Ley Modelo de Arbitraje no hizo referencia al orden público internacional porque consideró que este concepto era impreciso (Racine, 1999, pág. 481).

La distinción entre orden público interno e internacional ha sido aplicada por tribunales de Alemania, Italia y Suiza. Los tribunales de Dinamarca, Holanda, Noruega, España y Suecia han adoptando una posición restrictiva. En Italia, el tema se controvirtió en el ámbito judicial y doctrinario (Galgano y Marrella, 2010, págs. 
408-416). También en Inglaterra la cuestión se presenta dudosa, en consideración a que en el caso Kaufman vs. Gerson de 1904 se estableció que no existe distinción, pero en 1984 se afirmó lo contrario en el caso Israel Discount Bank of New York vs. Hadjipateras (O'Brien, 1999, pág. 281).

En cuanto a los instrumentos internacionales, la Convención de Nueva York, de 1958, sobre el Reconocimiento y la Ejecución de las Sentencias Arbitrales Extranjeras, emplea la expresión orden público a secas en el artículo $\mathrm{V}$, numeral 2, literal b. Sin embargo, la adecuada interpretación del artículo en mención, que es acogida en la mayoría de los países, se refiere al orden público internacional (Caivano, 1998, pág. 157).

El hecho de que la Convención de Nueva York se refiera al orden público de un determinado Estado no significa que simplemente se acoja de manera general el concepto que de este se aplica en materia interna. En efecto, la expresión orden público proviene de un texto internacional y, por ello, la delimitación de su contenido debe partir necesariamente del alcance internacional del instrumento (Cárdenas, 2007, pág. 79). Debe observarse que la Convención de Nueva York buscó promover el arbitraje internacional $y$, por tanto, su interpretación del concepto de orden público es restrictiva, es decir, de tal manera que no se afecte el desarrollo del arbitraje en dicho ámbito. La misma interpretación es aplicable a la Convención Interamericana sobre Arbitraje Comercial Internacional, de 1975, en el artículo 5, numeral 2, literal b.
Todas las convenciones de La Haya, luego de la Segunda Guerra Mundial, incluyen la cláusula de orden público internacional y en algunos casos emplean la palabra manifiesta, con lo que implícitamente acogen esta terminología (Rubino-Sammartano y Morse, 1991, págs. 1920). También hace parte de varios instrumentos convencionales interamericanos, como la Convención Interamericana sobre Eficacia Extraterritorial de las Sentencias y Laudos Arbitrales Extranjeros, en el artículo 2, literal h; la Convención Interamericana sobre Exhortos o Cartas Rogatorias, en el artículo 17, y la Convención Interamericana sobre Normas Generales de Derecho Internacional Privado.

Según el Convenio de Roma, de 1980, los Estados miembros pueden negarse a aplicar la ley foránea cuando se encuentra "manifiestamente incompatible" con el orden público. El término es recogido también por el Reglamento 44/2001, de la Unión Europea sobre jurisdicción internacional. La diferencia es reconocida en resoluciones del Instituto de Derecho Internacional y de la International Bar Association.

\section{A. Orden público procesal}

El orden público puede tener un carácter sustantivo o procesal. La doctrina ha establecido que los principios sobre los que se fundamenta el orden público sustantivo son el abuso de los derechos, la buena fe, la fuerza obligatoria del contrato, la prohibición de expropiación sin indemnización y la prohibición de actividades contrarias a las buenas costumbres, como la proscripción de la piratería, el terrorismo, el genocidio, la es- 
clavitud, el contrabando, el tráfico de drogas y la pedofilia (Cárdenas, 2007, pág. 85).

La falta o errónea motivación de un laudo arbitral internacional no es significativa de la violación del orden público internacional. De igual forma, el control judicial de un laudo arbitral no puede convertir al juez en un fallador que va a decidir nuevamente el litigio dirimido por arbitraje internacional, porque su función no es resolver el litigio, sino evitar el reconocimiento de una sentencia que viola el orden público internacional. Por tanto, el juez nacional no puede aceptar que por la vía del control se planteen nuevos hechos, pretensiones, oposiciones 0 nuevas pruebas (Cárdenas, 2007, pág. 105).

Desde un punto de vista procesal, la UNCITRAL ha señalado que debe negarse la ejecución de un laudo arbitral cuando en él ha habido fraude o corrupción, por cuanto se engaña al tribunal, como podría ser el caso de documentos falsificados en el caso European Gas Turbines S.A. vs. Westman International Ltd., en el que una de las partes presentó un reporte fraudulento de sus gastos, y la Cour d'Appel de París determinó que el laudo internacional fundado en prueba fraudulenta es contrario al orden público internacional francés. Sin embargo, debe precisarse que el fraude debe ser trascendental en la decisión y el fallo no debe ser adverso a quien propició el fraude (Cárdenas, 2007, pág. 91).

Igualmente, se ha señalado que se debe negar el reconocimiento y ejecución a un laudo que desconoce los principios del debido proceso. Conviene recordar que la Convención de Nueva
York establece como una casual para negar el reconocimiento del laudo, que la parte contra la que se invoca la sentencia arbitral no haya sido debidamente notificada de la designación del árbitro o del procedimiento de arbitraje, o no haya podido, por cualquier otra razón, hacer valer sus medios de defensa.

Cuando desde el punto de vista procesal se hace referencia al orden público se invocan también, como violación de este, varios escenarios distintos a la falta de notificación y a que la parte no haya podido hacer valer sus medios de defensa. En tal sentido, en las legislaciones de algunos de los países que han adoptado la Ley Modelo de la UnCITRAL, una de las causas de violación del orden público es la grave vulneración de las reglas de justicia natural (Cárdenas, 2007, pág. 92). Esta interpretación es apoyada por la normatividad del International Center for Settlement of Investment Disputes (ICSID), que establece como causal de anulación la violación grave de una norma de procedimiento.

La Cour de Cassation francesa, en el caso Excelsior Film Tv Srl vs. Societé UGC- PHOA y la Cour d'Appel de Zurich han determinado que la falta de imparcialidad del juez constituye una violación del orden público internacional, específicamente en un caso en el que el contrato contemplaba que el árbitro sería el abogado de una de las partes (Cárdenas, 2007, pág. 92).

La violación de la cosa juzgada es igualmente una infracción del orden público internacional, concretamente cuando un laudo es contradictorio a una decisión previa de una corte o tribunal 
arbitral en la misma materia (Capotorti, Sperduti, y Ziccardi, 1973, pág. 353).

Es axioma que el tratamiento desigual en el ámbito procesal es también una violación al orden público internacional. Otra forma de violación del orden público internacional puede darse cuando son inadecuadas o no se han efectuado las comunicaciones correspondientes al calendario procesal o al nombramiento del tribunal arbitral.

La inadecuada oportunidad para presentar las propias pretensiones $u$ oposiciones, al igual que los medios probatorios idóneos para demostrar los propios supuestos fácticos, representan una violación al orden público internacional.

La Cour de Cassation francesa en el caso Dalico, del 20 de diciembre de 1993, ha considerado que se viola el orden público internacional francés cuando las partes no tienen la misma oportunidad para nombrar a los árbitros (Fouchard et al., 1996, pág. 364).

En lo referente a la violación del orden público internacional en materia procesal, el Tribunal de Apelaciones en lo Civil de Séptimo Turno, con sede en Montevideo, Uruguay, en el caso Líneas de Transmisión del Litoral S. A. vs. Engenharia S/A (SEC 894, 20 agosto 2008), sostuvo que el debido proceso y el derecho de defensa implican que la presentación de cada parte deba ser expuesta al árbitro y que su actuación sea efectiva. El árbitro debe respetar los principios audiatur et altera pars. Es decir, los árbitros no pueden resolver la litis sin dar previamente a los litigantes la posibilidad de articular sus argumentos, propiciar el contradictorio, permitirles la presentación de medios probatorios y comunicar a la parte contraria todo lo relativo al proceso, para habilitar la posibilidad de impugnar los argumentos o pruebas. Los árbitros deben ajustar su actuación a los límites del acuerdo arbitral (Viana, 2007, pág. 140).

Un ejemplo para entender la distancia entre orden público procesal interno y auténtico orden público internacional de carácter procesal es el caso Direction General de l'Aviation Civil de l'Emirat de Dubai vs. Societé International Betchel Co., del 29 de septiembre de 2005, dirimido en la Cour d'Appeal Paris, en el que las Cortes del Estado contra el que fue proferido el laudo arbitral internacional lo anularon con el argumento de que algunos testigos fueron escuchados sin prestar juramento. La empresa favorecida obtuvo, con el arbitraje internacional, el reconocimiento de la Cour d'Appeal, por considerar que la violación de una norma imperativa del Estado de Dubái, la obligatoriedad de juramento del testigo, no era significativa de la violación del orden público internacional.

En materia de procedimiento arbitral, los aspectos formales que constituyen la noción de orden público internacional tienen que ver con el respeto al principio del debido proceso y al derecho de defensa (Viana, 2007, pág. 141).

El ideal orden público procesal radica en la obligatoriedad de garantizar un due process transnacional, que consiste en el respeto a la igualdad de las partes y el derecho a tener acceso 
al debate contradictorio. Mientras estos dos principios se respeten, los contratantes pueden acordar libremente el procedimiento que más se ajuste a las necesidades de la controversia (Mantilla-Serrano, 2004, pág. 100). Este derecho fundamental no puede ser monopolizado por una ley estatal o por algún código procesal civil.

Como puede observarse, existe coincidencia entre las reglas fundamentales del due process y las situaciones mínimas para evitar la violación del orden público internacional. Son condiciones equivalentes.

Se debe resaltar que las reglas o principios de violación del orden público internacional en asuntos procesales son aquellas que la doctrina y la jurisprudencia internacional dominante han catalogado como fundamentales, es decir, se aplica la teoría minimalista del orden público.

\section{B. Orden público en instrumentos de arbitraje internacional}

Los reglamentos de las instituciones dedicadas a la administración de arbitraje internacional consideran, especialmente, el respeto del orden público en una versión soft o minimalista.

Por ejemplo, el reglamento de arbitraje de la Corte Internacional de Arbitraje de la Cámara de Comercio Internacional, en el artículo 15, relativo a las reglas aplicables al procedimiento, en el literal 2 afirma que en todos los casos el tribunal arbitral ha de aplicar el procedimiento de manera equitativa e imparcial, velando porque a cada parte se le haya dado la posibilidad de ser suficientemente oída.

El artículo 15 del reglamento de arbitraje de la UNCITRAL afirma que el tribunal arbitral podrá dirigir el arbitraje del modo que considere apropiado, siempre que se trate a las partes con igualdad y que, en cada etapa del procedimiento, se otorgue a cada una de estas la plena oportunidad de hacer valer sus derechos. Además, establece que todos los documentos o informaciones que una parte suministre al tribunal arbitral los deberá comunicar simultáneamente a la otra parte.

\section{Estado transgresor del orden público}

El Estado y sus entidades por lo general tienen la opción de mantenerse bajo la jurisdicción de los tribunales estatales normalmente competentes o, por el contrario, en uso del principio de autonomía, someterse a la decisión de árbitros. Es decir, tienen la posibilidad de estipular o no un pacto arbitral, que es la norma en los casos de inversión privada en un Estado. Sin embargo, una vez ejercida esa opción no pueden escapar a ella o pretender modificar las condiciones de su ejercicio, desconociendo sus propios actos 0 , lo que es aún peor, abusando de sus prerrogativas. Un Estado que pacta un arbitraje y luego invoca su propio derecho para tratar de dejarlo sin efecto actúa de mala fe y abusa de sus prerrogativas. El Estado ni sus entidades públicas pueden invocar las prerrogativas de su propio derecho para sustraerse a las obligaciones dimanantes del pacto arbitral. 
El derecho suizo, al igual que la regulación española, consagra expresamente la prohibición de que un Estado se ampare en disposiciones o jurisprudencias nacionales para sustraerse a los efectos de un pacto arbitral.

Es violatorio del orden público internacional, además de los más mínimos principios de buena fe y honestidad contractual, que un Estado o una empresa u organización controlada por un Estado, que sea parte de un arbitraje internacional, se aproveche de su propia ley para disputar su capacidad de ser parte en el arbitraje o la arbitrabilidad de la controversia cubierta por el pacto arbitral. Resulta paradójico, pero acontece, que el verdadero orden público internacional es violado cuando un Estado, invocando un falso orden público internacional de fuente nacional, incumple sus obligaciones internacionales.

El artículo 27 de la Convención de Viena sobre el Derecho de los Tratados, impone que en un Estado predomine el derecho internacional sobre normas internas. Es decir, un Estado no puede alegar su propio derecho para desconocer sus obligaciones internacionales. Desafortunadamente, en algunas ocasiones los tribunales nacionales, para proteger normas imperativas de carácter interno, desconocen el derecho internacional y ponen en riesgo al propio Estado por la comisión de ilícitos internacionales.

El artículo 25, numeral 1 del Convenio de Washington, del ICSID, establece expresamente que si las partes han otorgado su consentimiento, ninguna de ellas podrá retirarlo de manera unilateral.

\section{Orden público internacional y normas imperativas}

Existen dos tesis en relación con el grado de control o amplitud del orden público: una maximalista y una minimalista. La primera postula una concepción amplia del orden público internacional, que incluya todas las leyes de policía y un control profundo de los laudos internacionales para verificar que el orden público esté siendo respetado, lo que induce a una peligrosa revisión de fondo de los laudos internacionales. La tesis minimalista considera que, aun en presencia de las leyes de policía o principios de orden público, el control del laudo por el juez de nulidad o ejecución debe ser mínimo y no puede anularlo o no ejecutarlo sino en casos excepcionales (Ubertazzi, 2006, pág.113).

La Cour d'Appel francesa ha sostenido que una ilicitud, para ser violatoria del orden público debe ser flagrante, efectiva y concreta; debe "quemarle los ojos al juez", con lo cual es evidente que ha adoptado la tesis minimalista del contenido de orden público y ha excluido de él no solo las normas imperativas, sino también las derivadas de políticas públicas (González de Cossío, 2008, pág. 68).

En esta medida, la doctrina y la jurisprudencia internacionales se han orientado en el sentido de señalar que el concepto de orden público en esta materia no se puede identificar con el de norma imperativa y orden público interno (Cárdenas, 2007, pág. 84). 
Acogiendo la posición de la Cour d'Appel francesa y de la más moderna tendencia, es preciso considerar un desacierto la afirmación de muchos trataditas que aseveran que el concepto de orden público, como causal de no ejecución de un laudo, debe incluir las normas imperativas (González de Cossío, 2008, pág. 66). No es un binomio obligatorio la violación de normas imperativas con violación del orden público internacional.

La Cour de Cassation en el caso Renault vs. Soc. c. 2000 Jaguar France International confirmó el carácter internacional y abandonó la criticada y profusa mención a las normas imperativas nacionales, para consagrar el orden público internacional como único límite a la voluntad de las partes.

La última reforma del Codice di Procedura Civile italiano, en lo concerniente al arbitraje internacional, en mi percepción confunde los conceptos de orden público y de normatividad imperativa. Ante todo, enumera motivos sustantivos y procesales para la anulación del laudo acogiendo la ruinosa tesis maximalista y enumerando entre las causales procesales varias materias que son ajenas al orden público, pero las impone expresamente como motivos para declarar la nulidad del laudo. Los vicios procesales o errores in procedendo generadores de nulidad en el Codice di Procedura Civile italiano, que incluso operan habiéndose renunciado a la impugnación, son la invalidez de la convención arbitral; la nulidad de la constitución del colegio arbitral si ha sido alegada en el juicio; la incapacidad del árbitro; la circunstancia de que los árbitros hayan superado los límites del convenio arbitral o decidido acerca de materias sobre las que no podían hacerlo; la falta de motivación o de la parte dispositiva del laudo o de la firma de los árbitros; el retraso en proferir la decisión; la discordancia del laudo con otro que no pueda ser ya impugnado o con una sentencia con efecto de cosa juzgada; el irrespeto al principio del contradictorio; la falta de la resolución de la cuestión de fondo, cuando esta sea necesaria; la contradicción entre la parte dispositiva y la decisoria; y la falta de pronunciamiento sobre algunas demandas o excepciones propuestas (Meo, 2008, pág. 121).

Asimilar la arbitrabilidad al orden público es error. Es cierto que existe una similitud conceptual, pero la hipótesis es diversa. Existen temas de orden público que son arbitrables, materias que no son arbitrables por ser de orden público y materias que son tanto de orden público como inarbitrables. La existencia de variables diversas necesariamente implica que no son lo mismo.

\section{ANACIONALIDAD DEL ORDEN PÚBLICO INTERNACIONAL}

En el esquema conflictualista, el orden público es protector de los sistemas jurídicos locales frente a los posibles resultados que podrían acontecer de permitir in abstracto la aplicación de un derecho extranjero, lo que ha sido descrito como jump into the dark (Rubino-Sammartano y Morse, 1991, pág. 8). La función principal del orden público es controlar el resultado alcanzado, 
es decir, constituye el instrumento para corregir el eventual error en la selección del derecho en cuanto al contenido, en razón a que obliga al juez a evaluar el resultado dado por la lex causae que debería resultar aplicable, examinando su compatibilidad con los principios básicos de justicia como resultan entendidos por la lex fori (Visher, 1993, pág. 100). De esta forma, el Estado del foro controla el derecho aplicable y determina las condiciones, los límites y el alcance de la autonomía de las partes en los contratos internacionales.

Siguiendo esta equivocada tesis se concluye que el orden público internacional es, en el fondo, nacional y no internacional, y que la distinción entre nacional e internacional resulta, en consecuencia, artificial. El adjetivo internacional se utiliza cuando el orden público opera en el ámbito del derecho internacional privado.

El artículo 1502 del Code de Procédure Civile francés menciona el orden público internacional. Comentaristas de gran reconocimiento sostienen que significa la concepción francesa del orden público internacional. En mi opinión, es una conclusión errónea, porque en realidad no es internacional. Es francés. Es decir, nacional. El derecho francés, al igual que todo derecho nacional, no puede convertirse en el dictatore del significado de un concepto que gravita en todo el planeta. De forma expresa, en Portugal, el artículo 1096, literal f, del Código de Processo Civil de 1986, se refiere al orden público internacional portugués. Es imposible conceptualmente hablar de orden público internacional agregándole un gentilicio como francés o portugués, porque deja de ser internacional para convertirse en orden público del Estado del gentilicio.

Es permanente la manera en que la jurisprudencia francesa califica el orden público desde la óptica interna por hacer continua referencia a la frase "concepto francés de orden público internacional", con lo que debe entenderse, como lo precisó su misma Cour de Cassation, que el orden público internacional comprende los principios de justicia universal considerados en la opinión francesa como dotados de valor internacional absoluto (Mantilla-Serrano, 2007, pág. 219).

Un fallo de 1958 de la Corte Internacional de Justicia, en un caso entre Holanda y Suecia, decidió que este último país no podía dar un contenido sueco a la noción de orden público, sino que debería tener en cuenta las prácticas e ideas de las naciones civilizadas (Van Houtte, 2002, págs. 845 y 846).

En materia estrictamente de arbitraje, la Convención de New York se refiere al orden público, con la denominación "del país". Algunos conciben esta acepción como la demostración de que el orden público internacional es relativo a la concepción de cada país. Nada más falso. Los negociadores de la Convención de New York lo que pretendieron fue armonizar el orden público y establecer un estándar internacional común, siendo conocido que la Comisión Redactora utilizó en su momento determinadas palabras, no adoptadas en el texto definitivo, alusivas al requerimiento de una clara compatibilidad con el orden público o principios fundamentales del 
derecho, lo que evidentemente lleva a una concepción más amplia, es decir, realmente internacional y no atada a alguna idea nacional del orden público internacional (Pereznieto y Graham, 2013, págs. 80 y ss.).

El juez estatal ejerce un control desde la perspectiva de los principios que gobiernan su propio orden público interno, por consiguiente no tiene competencia, en el sentido amplio de la palabra, ni atribución para disponer de la aplicación del orden público internacional. Es más, podría atreverme a afirmar que no existe conocimiento del orden público internacional por parte de los funcionarios judiciales, por cuanto lo confunden con el orden público interno.

Gran parte de los comentaristas afirman, confundiendo el orden público interno con el transnacional, que el primero, en relaciones contractuales internacionales, es concebido en interés del Estado y, como consecuencia, los particulares no tienen poder de disposición (Cárdenas, 2007, pág. 102). La conclusión es equivocada, porque parte de un supuesto errado; el orden público internacional no es concebido en interés de un Estado en particular sino de la comunidad internacional y, por tanto, no existe ningún instrumento o normatividad que prohíba, en abstracto, disponer de él. Es obvio que por motivos de seguridad jurídica y control de las relaciones contractuales debe existir un límite a la autonomía contractual, que, repito, no puede provenir engreídamente de un Estado en particular.

El orden público internacional debe ser caracterizado por restricciones exiguas de índole mini- malista. Tiene la debilidad de que su origen no está tipificado en algún instrumento internacional, seguramente por la dificultad de concordar ideas tan diferentes para un concepto que debe ser reconocido mundialmente para poderse denominar orden público internacional.

\section{A. Auténtico orden público internacional}

Desde mediados del siglo XX se ha hecho referencia a la idea de un orden público verdaderamente internacional, constituido por principios de justicia universal capaces de conformar una especie de ius Gentium (Laghi, 1888, pág. 19) o derecho común cosmopolita.

La Cour d'Appel de París, en 1966, anuló una transacción de tráfico de armas inspirándose en la noción de orden público verdaderamente internacional. En 1984 admitió un tipo de orden público, si no universal, al menos común a varios países (Kah-Freund, 1974, pág. 28). En fecha más reciente (1990) evocó la existencia de un orden público de esencia verdaderamente internacional y de aplicación universal (Delvolvè, 2003, pág. 286). En la misma línea, en 1993, sostuvo que la buena fe es un principio general de orden público internacional (Rossel y Prager, 2003, pág. 471).

Del examen de varios pronunciamientos se concluye la tendencia a reconocer cada vez con mayor fuerza, de manera directa u oculta, una noción más general del orden público, quizás supranacional, que pertenece a la más amplia comunidad transnacional o universal (Lalive, 1986). Se habla de un verdadero orden público 
internacional o true international public policy u orden público transnacional.

Es además concluyente y lógico que en la medida en que los árbitros no tienen foro, aplicarán los que consideran los requisitos de un verdadero orden público internacional (Fouchard et al., 1996, pág. 345).

La principal advertencia es que el orden público internacional resultaría útil si difiere del orden público nacional. Un juzgador podría acudir al auxilio del verdadero orden público internacional dejando de lado su propia ley, en razón de la prioridad que debe darse a la fuente internacional antes que a la nacional (Legarde, 1994, pág. 51).

La Rama Judicial de Uruguay ha dado muestra de concebir auténticamente el orden público internacional, al determinar que las causales que se deben invocar para anular un arbitraje internacional tienen que ser de origen internacional y no las previstas por la normativa interna uruguaya para los laudos domésticos. Consecuentemente, la anulación procede solo para el caso de que se haya violado en forma grave y manifiesta el orden público internacional, lo que equivaldría exclusivamente a las garantías del due process y del ejercicio del derecho de defensa de las partes (Viana, 2007, pág. 138).

Es evidente la creciente importancia que se viene dando en derecho internacional a la lex mercatoria o derecho transnacional emergente de normas comunes de distintos sistemas jurídicos.
El orden público internacional recibe la crítica de no ofrecer certeza, ni definición en cuanto a sus contornos, sustancia y aplicación (Álvarez, 2005, pág. 31).

\section{B. Paradigmas de orden público internacional}

Es posible afirmar que existen ejemplos de orden público transnacional, como el orden público comunitario, compuesto por valores fundamentales compartidos en zonas de integración regional. El Libro Verde de la Unión Europea expresa que cada Estado miembro dispone de su propio cuerpo de normas de orden público internacional (Autorino et al., 2013, pág. 25). Con la multiplicación de disposiciones dominantes y absolutas de origen comunitario, se asiste al nacimiento de un orden público europeo. También es posible identificar el surgimiento embrional de un orden público transnacional en otras zonas de integración, como el emergente del North American Free Trade Agreement (NAFTA) y del Mercosur.

Este orden público puede ser concebido a partir de valores transnacionales compartidos. En Europa, los jueces están obligados a tener en cuenta un orden público europeo o comunitario que se desprende de los antecedentes del Tribunal de Justicia de las Comunidades Europeas, y la especial legislación transnacional de la Unión Europea que constituye una organización supranacional cuyo derecho comunitario resulta directamente vinculante para sus Estados miembros. En cada uno de los Estados miembros el derecho comunitario hace parte del sistema 
jurídico nacional. De existir conflicto, prevalece el derecho europeo sobre el autóctono, lo que equivale a que el orden público nacional se diluya cada vez más (Van Houtte, 2002, pág. 848), hasta desaparecer, para existir únicamente un solo orden público, sin distinción entre europeo y nacional, es decir, un orden público realmente transnacional.

También se asiste al desarrollo de un orden público transnacional en temas específicos, como el orden público emergente de los convenios de inversión sometidos al IcsıD, firmado en Washington, en 1965 (Álvarez, 2005, pág. 31). Según su reglamento son improcedentes las impugnaciones de los arbitrajes internacionales ICSID ante tribunales locales, por lo que sus laudos pueden reputarse auténticamente anacionales o deslocalizados (Gonzalo Quiroga, 2003, págs. 39-48) y, por ende, sustraídos de particularidades locales de orden público.

Las reglas relativas al control público sobre inversión extranjera expresan la idea de un orden público económico internacional, porque estas apuntan a preservar en el interés público el balance entre las relaciones económicas y financieras con el resto del mundo al controlar el movimiento de capital transfronterizo.

\section{CONCLUSIONES}

Representa una desorientación conceptual hablar de orden público internacional agregándole un gentilicio como francés, colombiano o italiano, porque al hacerlo deja de ser internacional para convertirse en orden público del Estado del gentilicio. La demostración de su desacierto se encuentra en que si por absurdo fuera posible que cada país estableciera el concepto de orden público internacional, existirían tantos órdenes públicos internacionales como países. Conclusión que en la realidad transnacional es inadmisible, porque equivaldría a una inseguridad planetaria del concepto de orden público.

Cuando está involucrado un laudo de un arbitraje internacional no puede afirmarse, como lo hacen erróneamente varios comentaristas, que el laudo es inejecutable por ser violatorio del orden público en la medida en que repugne las nociones fundamentales de lo que es decente y justo en el Estado donde se busca la ejecución, porque en el ámbito del derecho internacional un laudo debe ser rechazado cuando repugne con las nociones básicas de lo que se entiende por orden público internacional sin que sea vinculante con algún concepto de orden público de un país determinado.

Para que una norma de interés social se eleve a rango de orden público como causal de invalidez de un laudo internacional tiene que tratarse de una noción básica de moralidad y de justicia del sistema jurídico relevante $y$, por tratarse de arbitraje internacional, el sistema jurídico relevante no puede ser un país determinado, sino el derecho transnacional, de donde se concluye que la fuente del orden público internacional no puede ser de origen estatal.

El orden público internacional no es concebido en interés de un Estado en particular, sino de la 
comunidad internacional y, por tanto, no existe ningún instrumento o normatividad que prohíba, en abstracto, disponer de este.

El arbitraje internacional ha tenido gran éxito reciente como eficaz mecanismo de solución de contiendas emergentes de contratos negociados paritariamente. No debe el arbitraje servir de instrumento para evadir disposiciones imperativas de protección cuya aplicación resulte ineludible en relaciones contractuales de determinadas características. Un pretendido libertinaje en la utilización del arbitraje puede causarle mucho daño.

El auténtico orden público internacional representa el legítimo freno a la posible extrema autarquía del contractualismo salvaje, y es garantía de justicia en el arbitraje internacional, pues permite que el arbitraje se nutra de sus principales características, entre las que se encuentra la autonomía contractual, particularmente en los asuntos procesales. El auténtico orden público internacional permite disponer de todas las cualidades del arbitraje internacional y limitarlo de sus eventuales abusos.

En círculos universales y regionales se patrocina cada vez con mayor ímpetu la necesidad de que se armonicen también las restricciones de origen imperativo, en aras de una más eficaz integración de los distintos sistemas jurídicos, apuntando a que las restricciones de orden imperativo sean no solo excepcionales, para no minar el principio de la autonomía de la voluntad, que es uno de los pilares de la contratación moderna, sino que las soluciones sean homogéneas, como está ocurriendo en la Unión Europea con las diversas directivas de orden imperativo que conciernen a la contratación internacional.

Lo ideal sería que las normas de origen imperativo estén armonizadas lo más posible, y para ello en mucho contribuirá seguramente la creciente sofisticación de la doctrina del orden público sumada a los procesos mundiales y regionales de homogeneización normativa.

Es de resaltar que las reglas o principios de violación del orden público internacional en asuntos procesales son aquellas que la doctrina y la jurisprudencia internacional dominante han catalogado como fundamentales. Es decir, se aplica la teoría minimalista del orden público.

Es violatorio del orden público internacional, además de los más mínimos principios de buena fe y honestidad contractual, que un Estado o una empresa u organización controlada por un Estado que sea parte de un arbitraje, se aproveche de su propia ley para disputar su capacidad de ser parte en el arbitraje o la arbitrabilidad de la controversia cubierta por el pacto arbitral. Es paradójico, pero acontece, que el verdadero orden público internacional sea violado cuando un Estado, alegando un falso orden público internacional de fuente nacional, incumpla sus obligaciones internacionales.

\section{Referencias}

Ahdab, A. y El Ahdab, J. (2011). Arbitration with the Arab Countries. The Hague: Kluwer Law International. 
Álvarez, H. (2005). Guiado por una mano invisible. El orden público al amparo del capítulo 11 del Tratado de Libre Comercio de América del Norte (tLCAN). Revista Peruana de Arbitraje, (1).

Angelini, F. (2007). Ordine pubblico e integrazione constituzionale europea: i principi fondamentali nelle relazioni interordinamentali. Padua: CEDAM.

Autorino, G., Noviello, D. y Troisi, C. (2013). Mediazione e conciliazione. Nelle controversie civli e commerciali. San Marino: Maggioli Editori.

Caivano, R. (1998). Reconocimiento y ejecución de laudos arbitrales extranjeros. En A. Pucci (Coord.), Arbitragem Comercial Internacional. São Paulo: Editorial LTr.

Capotorti, F., Sperduti, G. y Ziccardi, P. (1973). La giurisprudenza italiana in materia internazionale. Napoles: Jovene.

Carbonnier, J. (1971). Derecho Civil, (t. II, Vol. II). (M. M. Zorrilla Ruiz, Trad.). Barcelona: Editorial Bosch, S. A.

Cárdenas, J. P. (2007). Las causales que pueden ser declaradas de oficio para negar el reconocimiento de un laudo. Revista Internacional de Arbitraje, (6).

Cour d'Appel de Paris. Renosol France vs. Société Corevall North America. Febrero 15 de 1992.
Cour d'Appel de París. European Gas Turbines S.A. vs. Westman International Ltd. Septiembre 30 de 1993.

Cour d'Appeal Paris. Direction General de I'Aviation Civil de l'Emirat de Dubai vs. Societé International Betchel Co. Septiembre 29 de 2005.

Cour de Cassation. Messageries Maritimes. 1959.

Cour de Cassation. Excelsior Film Tv Srl vs. Societé UGC- PHOA. N. 95-17.285, marzo 24 de 1998.

Cour de Cassation. Renault vs. Soc. c. $2000 \mathrm{Ja}-$ guar France International, mayo 21 de 1993.

Delvolvé, J., Rouche, J. y Pointon, G. (2003).

French Arbitration Law and Practice. The Hague: Kuwer Law International.

Enneccerus, L., Kipps, T. y Wolff, M. (1953). Derecho Civil, Parte General (Vol. II). Barcelona: Editorial Bosch, S. A.

Fauvarque-Cosson, B. (2008). European Contract Law. Monaco: Bibliothèque de Droit Privé, Sellier European Law Publishers.

Fouchard, P., Gaillard, E. y Goldman, B. (1996). Traité de l'arbitrage commercial international. París: Litec.

Galgano, F. y Marrella, F. (2010). Diritto e prassi del commercio internazionale. Padova: CEDAM. 
González de Cossío, F. (2003). Orden público y arbitrabilidad: dúo dinámico del arbitraje. Revista Internacional de Arbitraje, (9), 61-83.

Gonzalo Quiroga, M. (2003). Orden público y arbitraje internacional en el marco de la globalización comercial (arbitrabilidad y derecho aplicable al fondo de la controversia internacional). Madrid: Editorial Dykinson.

Gutteridge, H. C. (1949). Comparative Law. An Introduction to the Comparative Method of Legal Study and Research (Second Ed.). Cambridge: Cambridge University Press.

Juenger, F. K. (2000). The Lex Mercatoria and Private International Law. Uniform Law Review, 5.

Kahn-Freund, O. (1974). General Problems of Private International Law. Leyden: Sijthoff.

Kegel, G. (1986). Fundamental Approaches. En K. Lipstein (Edit.), International Encyclopedia of Comparative Law. Tübingen: Martinus Nijhoff Publishers.

Lagarde, P. (1994). Public Policy. En K. Lipstein (Edit.), International Encyclopedia of Comparative Law (Vol. 3). Tübingen: Martinus Nijhoff Publishers.

Laghi, F. (1888). II dirritto internazionale private nei suoi rapport colle leggi territoriali. Bologna: N. Zanichelli.

Lalive, P. (1986). Transnational (or Truly International) Public Policy and International Arbitra- tion. VIIIth International Arbitration Congress. New York.

Lipstein, K. (1981). Principles of the Conflict of Laws: National and International. Boston: M. Nijhoff.

Mantilla-Serrano, F. (2004). Termorío: un duro golpe al arbitraje. Revista Internacional de Arbitraje, (1), 190-205.

Mantilla-Serrano, F. (2007). La autonomía del arbitraje internacional: ¿Hacia un arbitraje realmente autónomo? En Arbitraje internacional: tensiones actuales (págs. 207-240). Bogotá, D. C.: Comité Colombiano de Arbitraje, Legis.

Meo, G. (1991). Las novedades de las recientes reformas italianas en materia de arbitraje. Revista Internacional de Arbitraje, (8), 106-125.

O'Brien, J. (1999). Conflict of law. Londres: Cavendish Publishing Limited.

Oppetit, B. (2006). Teoría del arbitraje (E. Silva, F. Mantilla y J. Caicedo, Trads.). Bogotá, D. C.: Legis Editores.

Pereznieto, L. y Graham, J. (2013). Tratado de Arbitraje Comercial Internacional Mexicano. México: Editorial Limusa S. A.

Racine, J. P. (1999). L'arbitrage commercial international et l'ordre public international. Paris: Librairie Générale de Droit et de Jurisprudence. 
Rosell, J. y Prager, H. (2001). International arbitration and bankruptcy: United States, Frances and the ICC. Journal of International Arbitration, 18(4).

Rubino-Sammartano, M. y Morse, C. (1991). Public policy in transnational relationships. Boston: Kluwer Law and Taxation Publishers.

Second Circuit of U.S. Court of Appeals. Caso Parsons \& Whittermore Overseas Co. Inc. vs. Societé de L'Industrie du Papier, 508 F.2d 969 (Joseph Smith; diciembre 24 de 1974).

Supreme Court of the United States. The Bremen vs Zapata Offshore Co. N. 71-322, junio 12 de 1972.

Supreme Court of the United States. Scherk vs. Alberto-Culver Co., junio 17 de 1974.

Supreme Court of the United States. Mitsubishi Motor Corp. vs. Soles Chrysler-Plymouth Inc. N. 83-1569, julio 2 de 1985.

Tribunal de Apelaciones en lo Civil de Séptimo Turno. Líneas de Transmisión del Litoral S.A. vs. Engenharia S/A. SEC 894, agosto 20 de 2008.
Tribunal Fédéral suizo. Sentencia 4P.278, marzo 8 de 2006.

Ubertazzi, L. C. (2006). Annali italiani del dirritto d'autore, della cultura e dello spettaculo. MiIano: Giuffrè Editore.

Van Houtte, H. (2002). From a National to a European Public Policy, Law and Justice in a Multistate World: Essays in Honor of Arthur T. von Mehren. New York: Transnational Publishers Inc.

Vásquez Palma, M. F. (2006). Orden público y arbitraje internacional en el marco de la globalización comercial (arbitrabilidad y derecho aplicable al fondo de la controversia internacional). lus et Praxis [online] 12(2), 407-410.

Viana, H. (2007). Las causales de anulación en el arbitraje internacional no son las de la ley local. Tribunal uruguayo ratifica jurisprudencia. Revista Internacional de Arbitraje, (7), 134-140.

Visher, F. (1993). General course on private international law. En Hague Academy of International Law, Collected Courses (t. 232, Vol. I). Tübingen: Martinus Nijhoff Publishers. 